\title{
O Direito Ambiental e Suas Implicações na Saúde Humana
}

\author{
THE ENVIRONMENTAL LAW AND ITS IMPLICATIONS \\ IN THE HEALTH BEING
}

\section{RESUMO}

Considerando que a saúde do ser humano está intimamente vinculada à preservação dos recursos naturais e, conseqüentemente, o meio ambiente como um todo, com base na Constituição de 1988, que se preocupou em discutir as questões ambientais, e na Lei de Política Nacional do Meio Ambiente (Lei 6.938/ 81), entre outros, este artigo tem por objetivo apresentar a real necessidade de se remanejar as políticas existentes e implantar políticas públicas capazes de atuar de forma preventiva e mais efetiva, seja nas áreas urbanas ou rurais.

\section{Palavras-chave}

Meio Ambiente, Saúde, Direitos e Deveres, Políticas Públicas, Bem-Estar.

\section{ABSTRACT}

Considering that human health is intimately related to natural resources' preservation and consequently to environment as a whole, based on the 1988 Constitution, which was concerned in discussing environmental ques-

(*) Advogada e consultora ambiental, especialista em Direito Ambiental pela Faculdade de Saúde Pública e Faculdade de Direito da Universidade de São Paulo.

${ }^{* \star}$ ) Advogada atuante em Palmas/TO, especialista em Direito Ambiental pela Faculdade de Saúde Pública e Faculdade de Direito da USP, mestre em Direito Difuso e Coletivo pela Universidade Metodista de Santos/SP, e professora de Graduação e Pós-Graduação da Faculdade Católica de Palmas/TO.

$\left.{ }^{\star \star \star \star}\right)$ Advogada e consultora ambiental, especialista em Direito Ambiental pela Faculdade de Saúde Pública e da Faculdade de Direito da Universidade de São Paulo, Coordenadora da Ouvidoria da cidade de Santo André. 
tions, and on the law of National Policy of Environment (law 6.938/81), among others, this article aims to present the real necessity of renewing the existent policies and of implanting public policies able to act as a preventive and more efficient form as well in the urban areas as in the rural ones.

\section{Key-words}

Environment, Rights and Obligations, Public Policies, Well-being.

\section{INTRODUÇÃO}

O presente trabalho pretende demonstrar que a saúde humana e o meio ambiente estão ligados de maneira profunda. Os impactos nocivos ao meio ambiente, tais como, a poluição, a contaminação da água, a falta de saneamento e a incidência de mosquitos vetores de doenças, atingem de forma direta o ser humano. Dada a natureza transfronteiriça dos impactos mencionados, verificamos a importância da implantação de políticas públicas que atuem de forma preventiva tanto nas áreas urbanas, como nas rurais.

Partindo do pressuposto de que a saúde humana está diretamente relacionada ao meio ambiente, faz-se necessária uma leitura constitucional do tema. A Constituição Federal de 1988 tratou com muito critério as questões ambientais. Apesar de termos uma Lei de Política Nacional do Meio Ambiente (Lei n. 6.938/81), e ainda outras leis infraconstitucionais direcionadas à proteção do meio ambiente, este somente foi elevado a status de proteção constitucional com o advento da Carta de 1988. Por exemplo, o art. 225 da Constituição Federal dispõe o seguinte: "Todos têm direito ao meio ambiente ecologicamente equilibrado, bem de uso comum do povo e essencial à sadia qualidade de vida, impondo-se ao Poder Público e à coletividade o dever de defendê-lo e preservá-lo para as presentes e futuras gerações".

Sobre o assunto, Fiorillo (2003)(1), aponta que o mesmo pode ser estudado sob quatro aspectos fundamentais, levando-se em consideração que sua interpretação deve acontecer de acordo com a luz do art. 1ํ, inciso III também da Constituição Federal. Nesse diapasão, poderíamos subdividi-lo.

Segundo Fiorillo (2003)(2), o artigo explica imediatamente o que é o Direito Ambiental Material. Muito embora, o legislador não tenha definido

\footnotetext{
(1) Fiorillo, Celso Antonio Pacheco. Responsabilidade civil por danos causados ao meio ambiente. In: Direito ambiental na visão da magistratura e do ministério público. Belo Horizonte: Del Rey, 2003, pp. 133-134.

(2) Idem, ibidem, pp. 133-134.
} 
o que é meio ambiente, subtende-se que foi recepcionado o conceito do art. $3^{\circ}$, inciso I da Lei 6.938/81, que traz um conceito jurídico de meio ambiente: "(...) conjunto de condições, leis, influências e interações de ordem física, química e biológica, que permite, abriga e rege a vida em todas as suas formas". Contudo, a expressão "a vida em todas as suas formas", não é propriamente um conceito jurídico. Precisamos tomar conceitos da física, química e biologia, a fim de compreendermos a complexidade do que é "vida". No atual estágio científico qual o conceito de vida? Certamente poderemos considerar como tal, qualquer componente do DNA e do RNA. Assim, constatamos que o primeiro equívoco do Direito Ambiental na década de 1980 foi achar que a ciência referia-se apenas à flora e fauna.

Num segundo aspecto, o art. 225 aponta o que é bem ambiental, ou seja, quebra a dicotomia que existia na doutrina. Enseja uma nova categoria de bens, que não são públicos e nem privados. São os bens de uso comum do povo. Aqui estamos falando de todo e qualquer bem que preencha os requisitos da dignidade da pessoa humana. E como requisitos mínimos encontram-se elencados no art. 6 da Constituição, e dentre os quais podemos destacar: educação, saúde, trabalho, moradia, lazer, segurança, previdência social, proteção à maternidade e à infância, assistência aos desamparados, etc. Nos deparamos com uma aproximação muito estreita da correlação do meio ambiente, com a saúde e a dignidade da pessoa humana, compreendendo que saúde não é apenas o estado de "não-doença", mas perpassa algo muito maior.

Como terceira característica, verificamos que o art. 225 dispõe sobre o dever de defender e preservar a vida que pertence ao poder público e também à coletividade. Nesse aspecto fica claro que a principal razão de ser do Direito Ambiental reside no dever de defender e preservar a vida. É um direito que pode ser caracterizado como um direito preventivo. $E$ isto, vem reforçar nossa afirmação de que saúde não se concentra apenas em um estado da "não-doença".

Finalmente, num quarto aspecto, o art. 225 pode ser compreendido como, o primeiro direito que se preocupa com o futuro. Em seu texto é possível observar expressamente a preocupação com as gerações futuras, ou seja, preocupa-se com os direitos daqueles que ainda virão.

Feita a leitura teleológica do art. 225 da Constituição, percebemos com clareza que esta é uma visão constitucional do século XXI. E o Direito Ambiental não merece outra forma de tratamento. As questões que envolvem o meio ambiente encontram-se ligadas de forma muito direta ao homem. Por este motivo, a visão que concebemos hoje deve ser voltada ao antropocentrismo.

Rodrigues (2002) ${ }^{(3)}$, enfrenta a questão que gera muitas controvérsias na doutrina, trazendo críticas à visão antropocêntrica do meio ambiente,

(3) Rodrigues, M. A. Instituições de direito ambiental. v. 1. São Paulo: Max Limonad, 2002, pp. 52-53. 
para depois admiti-la desde que seja refutada a idéia do homem deter o poder de vida e morte das demais formas de vida.

Antunes (2002) ${ }^{(4)}$, faz um estudo profundo sobre a questão e conclui que "o fio condutor desta tese é a concepção de que a natureza e o meio ambiente são conceitos culturais e que só existem em função do ser humano". E completa: "a observação da natureza permitiu que o homem pudesse perceber as leis gerais que regem o funcionamento do mundo natural $e$, a partir daí, tirar generalizações e conclusões úteis para o mundo social".

Com fundamento nos autores supracitados podemos considerar que a visão antropocêntrica do meio ambiente caminha no sentido de corroborar com o uso sustentável dos recursos ambientais, e não no sentido do homem ser detentor de vida e morte das demais espécies. Nesse aspecto temos que analisar os estudos que estão sendo realizados na área da saúde: aqueles que envolvem questões bioéticas. Aqui, os conceitos que podem enquadrar as formas de vida são ainda muito difusos e merecem investigações e reflexões mais profundas.

\section{OS DIREITOS METAINDIVIDUAIS}

Com os chamados direitos de terceira geração surgiram os direitos metaindividuais, também conhecidos como interesses difusos e coletivos. A estes, por construção inicialmente da doutrina, foram acrescidos os chamados interesses (ou direitos) individuais homogêneos, que fazem parte do conceito do art. 81 do Código de Defesa do Consumidor:

Art. 81 - A defesa dos interesses e direitos dos consumidores e das vítimas poderá ser exercida em juízo individualmente ou a título coletivo.

Parágrafo Único - A defesa coletiva será exercida quando se tratar de:

I. interesses ou direitos difusos, assim entendidos, para efeitos deste Código, os trans-individuais, de natureza indivisível, de que sejam titulares pessoas indeterminadas e ligadas por circunstância de fato;

II. interesses ou direitos coletivos, assim entendidos, para efeitos deste Código, os transindividuais de natureza indivisível de que seja titular grupo, categoria ou classe de pessoas ligadas entre si ou com a parte contrária por uma relação jurídica base;

III. Interesses ou direitos individuais homogêneos, assim entendidos os decorrentes de origem comum.

(7) Antunes, P. de B. Dano ambiental: uma visão conceitual. Rio de Janeiro: Lúmen Júris, 2002, p. 121 e segs. 
Os conceitos dos incisos do art. 81 foram devidamente estudados por Grinover et al (2001) ${ }^{(5)}$, ao tecerem os seguintes comentários: "para designar os direitos difusos optou-se pelo critério da indeterminação dos titulares $e$ da inexistência entre eles de relação jurídica base, no aspecto subjetivo, $e$ pela indivisibilidade do bem jurídico, no aspecto objetivo". No que se refere à prática:

(...) os operadores do Direito têm fragmentado os interesses ou direitos "difusos", e mesmo os coletivos, atribuindo-os apenas a um segmento da sociedade, como os moradores de um Estado ou de um Município. Assim agindo desnaturam por completo a "natureza indivisível" dos interesses, ou direitos trans-individuais, atomizando os conflitos, quando o objetivo do legislador foi o de submetê-los à apreciação judicial na sua configuração molecular, para assim se obter uma tutela mais efetiva e abrangente. $E$ ainda desconsideram esses profissionais o disposto no art. 103, I do Código de Defesa do Consumidor, que prevê a coisa julgada erga omnes ${ }^{(6)}$.

Os Interesses ou Direitos Coletivos foram conceituados no inciso II, do art. 81 do Código de Defesa do Consumidor. Segundo os autores nos interesses e direitos coletivos: "a relação jurídica base é preexistente à lesão ou ameaça de lesão do interesse ou direito do grupo, categoria ou classe de pessoas. Não a relação jurídica nascida da própria lesão ou da ameaça de lesão"(7).

Reforçando este entendimento os mesmos autores citam Barbosa Moreira ${ }^{(8)}$ que leciona o seguinte: "o interesse para o qual se reclama tutela pode ser comum a um grupo mais ou menos vasto de pessoas, em razão de vínculo jurídico que une as pessoas entre si, sem, no entanto, situar-se no próprio conteúdo da relação plurissubjetiva".

Quanto aos interesses Individuais e Homogêneos, descritos no inciso III do art. 81 , temos que "a homogeneidade e a origem comum são os requisitos para o tratamento coletivo dos direitos individuais. A origem comum pode ser de fato ou de direito, e a expressão não significa, necessariamente, uma unidade factual e temporal/(9)".

Assim, podemos assegurar que os direitos metaindividuais, surgem portanto, no contexto do Estado Democrático de Direito, demonstrando encontrarem-se consolidados no atual ordenamento jurídico brasileiro, vinculado às chamadas tutelas coletivas.

(5) Grinover, A. P. et al. Código brasileiro de defesa do consumidor. 7. ed. Rio de Janeiro: Forense, 2001, p. 737 e segs.

(6) Idem, ibidem, p. 737 e segs.

(7) Idem, ibidem, p. 737 e segs.

(8) Idem, ibidem, p. 737 e segs.

(9) Idem, ibidem, p. 737 e segs. 
Essa influência sofrida pela sociedade brasileira se deveu à sua inserção num contexto econômico-social globalizado, que findou por submetê-la ao aumento da interdependência do sistema jurídico em relação ao seu ambiente externo, o que, por conseqüência, passou a exigir uma nova postura diante daquilo que se convencionou chamar de sociedade de massas.

No âmbito da chamada sociedade de massa podemos assegurar que a visão individualista foi totalmente superada, quebrando-se assim a dicotomia entre o público e o privado.

Os conflitos de massa não eram evidenciados antes do surgimento desta nova sociedade. A partir da evolução desta última é que os interesses metaindividuais tiveram maior relevância. Daí surgiu a necessidade de mudança no processo que, até então, era voltado apenas para os conflitos individuais.

\section{O DIREITO AMBIENTAL COMO INTERESSE DIFUSO}

O Direito Ambiental passou a ser considerado pela doutrina como parte integrante dos direitos fundamentais de terceira geração conforme a conhecida classificação, que nos traz Moraes (2002)(10), como os direitos fundamentais de primeira, segunda e terceira gerações, baseando-se na ordem cronológica que passaram a ser institucionalmente reconhecidos. Segundo o autor, "os direitos fundamentais de primeira geração são os direitos e garantias individuais e políticos clássicos (liberdades públicas), surgidos institucionalmente com base na Magna Carta de 1215".

Em seguida, Moraes (2002)(11), aponta os direitos de segunda geração, considerando assim, aos chamados direitos econômicos, sociais e culturais, surgidos no início do século $X X$, sobre os quais se pronunciou Themístocles Brandão Cavalcanti(12):

(...) o começo do nosso século viu a inclusão de uma nova categoria de direitos nas declarações e, ainda mais recentemente, nos princípios garantidores da liberdade das nações e das normas da convivência internacional. Entre os direitos chamados sociais, incluem-se aqueles relacionados: ao trabalho, ao seguro social, à subsistência, ao amparo à doença, à velhice, etc.

Por fim, quanto aos direitos de terceira geração Cavalcanti(13), afirma:

Protegem-se, constitucionalmente, como direitos de terceira geração, os chamados direitos de solidariedade ou fraternidade, que englo-

(10) Moraes, A. Constituição do Brasil interpretada. São Paulo: Atlas, 2002, p.166.

(11) Idem, ibidem, p.166.

(12) In: Idem, ibidem, p. 167.

(13) In: Idem, ibidem, p.167. 
bam o direito a um meio ambiente equilibrado, a uma saudável qualidade de vida, ao progresso, à paz, à autodeterminação dos povos e a outros direitos difusos, que são os interesses de grupos menos determinados de pessoas, sendo que entre elas não há vínculo jurídico ou fático muito preciso.

Nesse sentido, podemos dizer que os direitos dos povos, ou de solidariedade internacional buscam, em última instância, estabelecer uma moralidade política internacional tendo em vista o desenvolvimento de um mundo mais justo, pacífico e solidário, ou seja, um mundo efetivamente democrático. É aqui que se inserem os direitos humanos difusos, configurando interesses transindividuais: bens que não podem por si serem definidos como de alguém ou de algum grupo social, tais como o ar que respiramos, o meio ambiente em que vivemos, etc.

Entendemos a importância da classificação ofertada acima, principalmente no que se refere ao reconhecimento dos direitos transindividuais. No entanto, para o Direito Ambiental, objeto deste estudo, tal classificação poderia ser considerada, até certo ponto, redundante. Desse modo, ao analisar os arts. 1, inciso III, e art. 6ㅇ, ambos da Constituição Federal, verificamos que não fazem referência ao meio ambiente de forma direta, e sim ao homem que nele vive. Reforçamos a visão antropocêntrica que devemos ter quando estudamos o direito ambiental, compreendendo que os direitos ditos de terceira geração são direitos naturais do homem, desde que ele apareceu na face da terra, mas que apenas recentemente, em termos de direitos, é que começaram a ser estudados e discutidos.

Bobbio (1992)(14), ensina que os direitos nascem quando podem ou quando devem. Em suas palavras:

Os direitos do homem, por mais fundamentais que sejam, são direitos históricos, ou seja, nascidos em certas circunstâncias, caracterizadas por lutas em defesa de novas liberdades contra velhos poderes, e nascidos de modo gradual, não todos de uma vez e nem de uma vez por todas.

Isto demonstra que o interesse sempre é erigido à categoria de direito de acordo com a necessidade da época em que se vive. Ou seja, a realidade do século $X X I$ é completamente diferente da realidade de outrora.

Considerando que o direito nada mais é do que um produto cultural, um fenômeno da pessoa humana, conforme o disposto na Constituição Federal nos arts. 215 e 216, é possível dizermos que a questão da lesão ou

(14) Bobbio, N. A era dos direitos. Rio de Janeiro: Campus, 1992, p. 5. 
ameaça aos direitos materiais e metaindividuais passou a ganhar maior relevância com a evolução da chamada sociedade de massa. Anteriormente, os conflitos de massa não eram evidenciados. A partir da evolução desta sociedade é que os interesses metaindividuais passaram a ter maior relevância. É daí que surgiu a necessidade de mudança no processo que, até então, era voltado apenas aos conflitos individuais.

Então, podemos considerar que os fenômenos das grandes transformações se materializam nos seguintes fundamentos:

- Na forma de manifestação do Estado.

- Na própria sociedade

- Na tutela dos interesses metaindividuais

- Na adequação da magistratura, na figura de um juiz mais ativo.

- Na adequação da tutela jurisdicional.

É dentro deste quadro evolutivo que devemos enxergar o direito à saúde como um bem ambiental, pertencente a todos indistintamente. Também devemos ressaltar que o direito à saúde a que nos referimos é mais que o direito à "não doença": importa em um meio ambiente sadio e capaz de proporcionar vida digna às pessoas independentemente de classe social. Entretanto, entendemos que isto somente será possível com a adequação das cinco grandes transformações acima apontadas, pois para ter um quadro satisfatório de saúde é preciso que haja manifestação do Estado na forma de prestar serviços adequados, tanto no âmbito da saúde como da vigilância sanitária; é preciso haver a colaboração da sociedade, na medida que esta possua um perfil mais participativo. Ademais, com a segurança de obtenção da tutela dos interesses metaindividuais passamos a ter assegurado o direito das massas que antes eram desassistidas, sendo que é imprescindível conscientizar os juízes, bem como, os demais operadores do direito para atuarem de forma mais ativa diante dos problemas que chegam ao judiciário; e finalmente, adequar a tutela jurisdicional, no sentido que abrigue aos que dela necessitem.

\section{INTERAÇÃO ENTRE O HOMEM E O MEIO AMBIENTE}

O homem é seguramente o ser que mais depende do meio ambiente. Mencionando primeiramente os recursos naturais, lembramos, que o homem não sobreviveria nem mesmo cinco minutos se não houvesse à sua disposição o recurso ar atmosférico; também não poderia ficar privado da ingestão de água, já que este recurso compõe $2 / 3$ do organismo humano. Ainda, o ser humano necessita ingerir alimentos e interagir com vários ele- 
mentos na natureza. Além desses aspectos apresentados, o homem necessariamente precisa conviver com outros seres humanos.

À medida que o tempo passa, é natural que ocorram mudanças inerentes à evolução do homem no meio em que vive, tais como o crescimento da população, o aparecimento de novas doenças e o respectivo tratamento, ou seja, o desenvolvimento da tecnologia em uma velocidade cada vez maior em contrapartida ao uso dos recursos naturais.

Assim, ao analisar o homem quanto ao uso dos recursos naturais do meio ambiente, é como se esses fossem inesgotáveis. Porém, a falta de condições adequadas, reflete na vida deste homem, na forma de doenças ou de falta de resistência a estas, contribuindo para a proliferação das doenças consideradas como físicas.

Por outro lado, as pressões sociais, como o desemprego, a falta de alimentação adequada e as demais formas de violências que sofre o ser humano contribuem para agravar o estado de saúde mental. Pois, como já dissemos antes, o bem-estar físico é necessário para considerarmos o indivíduo sadio. Assim, diversos são os fatores necessários, para que ao longo do tempo, o homem possa adaptar-se para seguir sua marcha.

Em decorrência desta necessidade de adaptação, o homem atual, diferentemente de seu antepassado que adaptava suas atividades à sua associação com a vida natural, utiliza a comunidade biótica de acordo com suas necessidades, e digamos de passagem, são cada vez maiores, ou melhor, inesgotáveis. Em nossos estudos constatamos que, quanto mais desenvolvido, maiores necessidades de consumo tem o homem. Isso conseqüentemente atinge o meio ambiente.

O que questionamos nesta capacidade infinita de consumo do homem moderno, é se ele será capaz de impor limites quebrando a cadeia do consumo exagerado, que por seu turno, retorna ao meio ambiente em forma de resíduos sólidos, efluentes não tratados, emissão de gases tóxicos, dentre outros.

Também questionamos se o homem moderno está devidamente conscientizado de que os recursos naturais são finitos, e que uma vez constatada esta finitude terá posto em risco a sua sobrevivência.

Dado o atual desequilíbrio dos diversos recursos do meio ambiente, provocados pelo aumento da população e pela forma como tem acontecido, já não se admite que tenhamos apenas uma atitude passiva. É necessário que haja comprometimento de múltiplos setores (poder público, empresas privadas, $\mathrm{ONGs}^{(15)}$, associações e coletividade em geral), no sentido de pensar novos meios de produção (como por exemplo, M P + L "modo de produ-

(15) Organizações Não-Governamentais. 
ção mais limpa), novas soluções que propiciem uma vida mais digna ao homem que é o destinatário central do meio ambiente.

Desde o seu surgimento na Terra o homem passou por várias transformações. Contudo, hoje podemos considerar que as modificações sofridas por este têm sido de forma por demais acelerada e, em escala assustadoramente maior. Iniciamos esta reflexão lembrando as palavras do Cardeal Suenes ditas em 1968: "a diferença hoje entre um homem de 20 anos e outro de 40 não é de apenas 20 anos; é de dois séculos. Porque o que levava um século para acontecer, hoje acontece em uma década; o que levava uma década, precisa hoje de apenas um ano".

Assim, é fundamental conscientizar a humanidade quanto às conseqüências advindas não só do mal uso dos recursos naturais, mas no que diz respeito às questões sociais que vem se agravando de forma preocupante.

\section{A SAÚDE E O MEIO AMBIENTE NA CONSTITUIÇÃO FEDERAL}

A Constituição Federal de 1988, elencou no seu art. 6ํㅜㄹ entre os Direitos Sociais à saúde, como direito inquestionável e inerente a todo ser humano; o art. $4^{\circ}$, inciso II, por seu turno, demonstra a preocupação do País em consagrar a prevalência dos direitos humanos; o art. 5ㅇ dispõe sobre a inviolabilidade do direito à vida; o art. 170 preza dentre outros, uma existência digna bem como, a garantia de defesa do meio ambiente; o art. 194 faz menção expressa ao direito à saúde, quando trata da seguridade social e, o art. 196, coloca de forma clara a obrigação do Estado de prestar os serviços de saúde de forma universal e igualitária.

Partindo da leitura teleológica dos artigos supramencionados, fomos remetidos de forma direta ao art. 225, também da Constituição concluindo junto com Santos (2002) $)^{(16)}$, que:

Daí se infere a importância essencial do meio ambiente e dos mecanismos que o protejam e preservem, para que sejam fornecidos fundamentos para o estabelecimento da saúde. Claro está que só o meio ambiente não assegura a saúde, mas é elemento indispensável, sem o qual aquela deixa de existir. Desse modo apreende-se que o legislador constituinte optou por tutelar de forma imediata a qualidade do meio ambiente e de forma mediata a saúde, o bem-estar e a segurança da população, que se vem sintetizando na expressão qualidade de vida.

Desta forma, podemos verificar que a saúde foi tratada de maneira criteriosa pela Constituição de 1988. Em seguida, já em 1990 houve duas

(16) Santos, C. L. dos. Os crimes contra o meio ambiente: responsabilidade e sanção penal. 3. ed. São Paulo: Juarez de Oliveira, 2002, p. 99. 
leis que vieram regulamentar o disposto na Constituição: Lei n. 8.080/90 e Lei $n$. 8.142/90, que tratam respectivamente sobre as condições para a promoção, proteção e recuperação da saúde, bem como, da organização e do funcionamento dos serviços correspondentes e, da participação da comunidade na gestão do SUS (Sistema Único de Saúde), e sobre as transferências intergovernamentais de recursos financeiros na área da saúde, além de outras providências.

É importante ressaltarmos que a Lei n. 8.080/90 praticamente repete os conceitos da OMS (Organização Mundial de Saúde), bem como a sua principiologia. A Organização Mundial de Saúde conceitua saúde como: “(...) estado de completo bem-estar físico, mental e social e não meramente a ausência de doença ou enfermidade". O que evidencia a simetria existente com a Lei brasileira é a unidade de desígnios entre o conceito da Organização Mundial de Saúde e o art. 3ำ da referida Lei que determina:

Art. 3- - A saúde tem como fatores determinantes e condicionantes, entre outros, a alimentação, a moradia, o saneamento básico, o meio ambiente, o trabalho, a renda, a educação, o transporte, o lazer e o acesso aos bens e serviços essenciais; os níveis de saúde da população expressam a organização social e econômica do País.

Resta assim, a evidente preocupação com a qualidade de vida do ser humano. Souza (2003)(17), se utiliza do conceito de qualidade de vida formulado por Wilheim \& Déak ao relatar: “(...) é a sensação de bem-estar do indivíduo. Este é proporcionado pela satisfação de condições objetivas (renda, emprego, objetos possuídos, qualidade de habitação) e de condições subjetivas (segurança, privacidade, reconhecimento, afeto)".

Portanto, devemos reconhecer que o legislador constituinte foi extremamente eficaz ao proteger a saúde de forma mediata e o meio ambiente de forma imediata, já que este reúne em seu bojo os requisitos necessários à proteção da saúde como um todo e conseqüentemente, o aumento da qualidade de vida. Também devemos compreender que os níveis de saúde de uma determinada população expressam de forma direta a organização social e econômica de um determinado local.

A própria Lei n. 8.080/90 expõe alguns princípios norteadores do direito à saúde no seu art. $7^{\circ}$, incisos de I a XIII. O Princípio da Universalidade, contido no art. 196 da Constituição Federal, dispõe: "a saúde é direito de todos e dever do Estado, garantido mediante políticas sociais e econômicas que visem à redução do risco da doença e de outros agravos e ao acesso universal e igualitário às ações e serviços para a sua promoção, proteção e recuperação". Aqui fica evidenciada a imprescindibilidade da prestação do serviço de forma acessível e igualitária a todos.

(17) Souza, J. C. Qualidade de vida. In: http://www.noticias.ucdb.br, acesso em Dezembro de 2003. 
A fim de compreendermos a amplitude do Princípio da Igualdade da Assistência à Saúde, devemos nos remeter ao art. 5ำ da Constituição, viga mestre dos direitos e garantias fundamentais, pois, ao mesmo tempo em que contém de forma expressa o direito à igualdade, traz a inviolabilidade do direito à vida. Assim, o princípio apenas repete a determinação constitucional.

Por fim, o Princípio do Direito à Informação também encontra abrigo na Constituição Federal ao expor que todos têm o direito de ser informados de forma clara sobre sua saúde. É certo, porém, que o profissional da saúde deverá estar atento e avaliar os casos em que a informação poderá, ao contrário, prejudicar o estado de saúde do homem.

\section{BIBLIOGRAFIA}

1. ANTUNES, P. de B. Dano ambiental: uma visão conceitual. Rio de Janeiro: Lúmen Júris, 2002.

2. BARBOSA, M. In: GRINOVER, A. P. [et a]]. Código brasileiro de defesa do consumidor. 7. ed. Rio de Janeiro: Forense, 2001.

3. BOBBIO, N. A era dos direitos. Rio de Janeiro: Campus, 1992.

4. CAVALCANTI, T. B. In: MORAES, A. Constituição do Brasil interpretada. São Paulo: Atlas, 2002.

5. FIORILLO, Celso Antonio Pacheco. Responsabilidade civil por danos causados ao meio ambiente. In: Direito ambiental na visão da magistratura e do ministério público. Belo Horizonte: Del Rey, 2003.

6. GRINOVER, A. P. [et al]. Código brasileiro de defesa do consumidor. 7. ed. Rio de Janeiro: Forense, 2001.

7. MORAES, A. Constituição do Brasil interpretada. São Paulo: Atlas, 2002.

8. RODRIGUES, M. A. Instituições de direito ambiental, v. 1. São Paulo: Max Limonad, 2002.

9. SANTOS, C. L. dos. Os crimes contra o meio ambiente: responsabilidade e sanção penal. 3. ed. São Paulo: Juarez de Oliveira, 2002.

10. SOUZA, J. C. Qualidade de vida. In: http://www.noticias.ucdb.br, acesso em Dezembro de 2003. 